\title{
Research on Credit Rating of Weak Credit Group based on Block Chain Technology
}

\author{
Junsheng Wang ${ }^{1, a}$, Erbao Nie ${ }^{2, b}$ and Jiuxin Cui ${ }^{2, c}$ \\ ${ }^{1}$ Beijing Huitong Financial Information Technology CO.LTD, Beijing 100053, China \\ ${ }^{2}$ State Grid Electronic Commerce CO.LTD. Beijing 100031, China \\ ${ }^{3}$ Beijing Huitong Financial Information Technology CO.LTD, Beijing 100053, China \\ a19158382@qq.com, bjingchalang@163.com, 'ccuijiuxin@sgitg.sgcc.com.cn
}

Keywords: Weak Credit; Campus Loan; Block Chain.

\begin{abstract}
This paper discussed how to solve the credit problems of weak credit groups in consumer credit, such as "campus loan". It put forward the block chain technology to modify the framework scheme and preliminary design of the architecture, provide a useful reference for the development of similar information intermediary system.
\end{abstract}

\section{Introduction}

Weak credit group refers to the capital market of credit information is not complete, the low level of credit quality, risk, slow release space smaller groups, does not include the lack of credit records but its own strong liquidity creation ability, or individual financing channels, consumer credit loan main body, such as "borrowed" campus obviously with such features.

In the traditional capital market, owning to various reasons the weak credit groups couldn't obtain credit rationing. Although its willingness to take high interest rates, but financial institutions for risk prevention and control of the reasons, the financial institutions does not favor high agency cost individual. In recent years, the rise of Internet banking, provide access to liquidity for weak credit groups the traditional capital market cannot cover. They obtain financial support, at the same time they need to pay a higher cost of capital. To a certain extent, ease the small and medium-sized enterprises, lower income, personal credit problems, but at the same time, the lagging behind of credit reporting technology also produced such as "naked" loan, as well as the "meat of" phenomenon, the negative impact on the development of the Internet finance.

Block chain technology with its intelligent protocol and distributed characteristic[1], for weak group's solvency and credit repayment willingness to undertake reasonable evaluation, and for the borrower to provide credit history by the time stamp which not be changed. If the credit risk pricing process using block chain technology on the Internet financial consumer credit products, assessment mechanism based on the "block chain +" in the center and to the center of the two-way risk to solve the above problems. It will be an effective supplement to existing credit system, with the central bank's credit reporting systems play a complementary role.

\section{Analysis on the transaction structure of "campus loan" weak credit group}

Internet finance's boom has created a lot of problems, these problems in 2015 and gradually appeared, interfered with the financial order, resulting in adverse social impact. In view of this, regulators in August 2016 introduced the Internet financial regulation, regulated the positioning of the Internet financial institutions and business content, and set the provisions of the adjustment period.

After the landing of regulatory measures, Internet finance companies have to carry out the transformation, many of which will focus on the field of consumer credit agency [2]. Consumer credit field can be divided into traditional areas and the rise of the Internet in the field of financial consumption. Among them, the traditional consumer credit focused on car and housing loans, while 
the Internet is more concerned about the field of financial consumption is a small amount, low levels of age such as 3C loans. Especially from the beginning of the second half of 2015, the explosive growth of Internet finance, and the asset side competition becomes more intense, more Internet financial capital to enter the campus, suburban farmers, rural areas, thus forming the structure of the transaction has the following main features:

\subsection{The borrower information asymmetry problem is more serious}

In the university campus, the average loan borrowers are young adults who have not yet entered the society. They are not independent economic individuals. They are curious about new things. As the main campus consumer loans, credit records of university students have been focused on student loans, credit information only through the registration and archival records to obtain, but due to the confidentiality of personal information or records management regulations and other reasons, the information acquisition and filtering are very difficult. Issuance of consumer credit products campus institution or organization didn't have the same borrower credit information platform or the database. There is no information exchange mechanism. The same borrower to obtain loans from multiple institutions can't effectively eliminate the phenomenon of frequent. In the case of frequent lend the same borrower, raising the borrowing main body of the cost of capital, and magnify the credit risk.

Investors couldn't obtain more comprehensive credit information of the loan object, but also failed to develop targeted credit risk pricing technology, creates the external conditions for this type of borrowers to become weak credit groups.

\subsection{The main body of the campus credit belongs to the weak credit group, and the credit quality is on low level}

The main body of the college students' consumption credit is the individual whose income level is low or the individual will change their own consumption environment. The borrower debt is the main source of parents to provide living expenses or income for migrant workers. Under the background of Chinese traditional culture, parents will provide easy consumption support for the children as much as possible, but for consumer credit, such behavior has a different identity. Borrowers in financial institutions or similar institutions to apply for loan from the Internet, for various concerns may not have to show a case, the main capital provider (parents), on the basis of the original cost of living increase of consumer loan without a stable source of repayment, cause the borrower's cash flow pressure, increased likelihood of default.

Overall, the campus consumer loan principal repayment ability is weak, the credit degree is low, basically belongs to the weak credit group category, which constitute the campus consumer credit products the risk of central uplift in the internal conditions.

\subsection{The structure of transaction design is not reasonable.}

There are three parts in the current campus loan transaction structure, including investors, information intermediaries and borrowers. Among them, investors are mainly Internet financial institutions, organizations or individuals without business registration but there is a certain ability to lend money, lack of industry standards and regulatory measures; information intermediary credit information is usually grey data transfer software company, and third party institutions does not have professional provides technology and services; the borrower is composed of weak credit groups mentioned above.

The structure of the transaction, the borrower credit risk pricing process completed by the third party to help investors or investors, can according to the credit information is very limited, for the assessment of the borrower's credit record and the repayment ability based on qualitative analysis, the so-called "big data credit" only model (depth analysis of historical data is not short of campus loan support time series), but not for the development of practical technology mature and reliable[3]. In order to avoid risks, investors in the debt contract design as far as possible to improve the borrower default cost terms, such as "naked" and "meat compensation" in violation of the general credit market norms, continue to challenge the moral bottom line out of contract.

In the unreasonable transaction structure, Campus consumer loans by the driving of the internal (weak credit group) and external (weak credit group) conditions, the credit risk [4] release more likely, moral risk, social risk management, etc. became increasingly serious. 


\section{Analysis of the causes of consumer credit problems of weak credit groups}

\subsection{Excess liquidity in relation to such credit}

In recent years, the shadow of the global financial crisis been lingering, the Chinese economy entered a long "L" period. In order to effectively boost the economy, the management will increase the willingness to stimulate consumption, thus liquidity conditions are ripe.

The Internet financial field has benefited from the rapid growth of the Internet financial products, funding sources are more abundant, but the assets are limited by the weak insufficient-allocated credit market which can only exploit the traditional capital market, with the high agency cost, sufficient credit supply, increasingly fierce competitions for assets side. Liquidity appears excess compared to the limited assets side.

\subsection{The relatively fragile credit relationship}

Consumer credit, especially such as "school loan" products, located in the "scattered, small, short-term, high profits", however, there is a mismatch between the positioning of such products and the actual operation.

First of all, the characteristic of small and scattered loans is not obvious. Many of these products, the loan amount are generally in the thousands to tens of thousands. The loan amount is not large, but the situation that the weak credit group's repayment ability and loan amount did not take into account. When the borrower maintains the necessary expenses, the remaining cash flow level is unlikely to effectively cover the debt principal and interest in the duration of the debt. Short-term debt's tightening of the time constraints and the high interest rate level makes the borrower risk mitigation space even worse.

As a result, the credit relationship based on the high returns of investors and the weak credit characteristics of borrowers is extremely fragile, and the contractual conditions required by the borrowers are often beyond the normal range, resulting in a greater likelihood of bad debts, so the default level may well be higher than initially estimated. In order to recover costs and ensure a certain profit, investors further push up the level of interest rates and the design of more onerous terms.

Further increase in the likelihood of debt repayment ability of borrowers, the risk of default, and the credit market risk release further intense [4], resulting in an accelerated feedback spiral.

\section{Constructing the pricing system of consumer credit risk based on "block chain +"}

Different from the usual block chain technology, the "block chain + " technology is based on decentralized transaction and data acquisition, centralized data return and centralized management as the model of credit system model [5], specifically include:

\subsection{Front-end block chain data collection module (module 1)}

With the rapid development of intelligent mobile phone and the massive popularity of mobile Internet technology, mobile phone APP becomes the effective carrier of social financial media. Chain blocks decentralized module mainly in the form of mobile phone APP or computer client can be a front-end information collector of consumer loans, where the borrower can obtain loan application information released by the module of social channels and investors can use this module to release the loan information. This module is required outstanding social function, friendly interface, a point-to-point or group lending network etc. through a variety of ways to add acquaintances or strangers. This module is a representative of the success of "Lending Treasure".

\subsection{Middle-end "block chain +"credit risk pricing module (module 2)}

At present, the credit risk pricing technology for weak credit group is seriously lagging behind, although numerous models emerge in an endless stream, but what can effectively solve the pricing problem of weak credit groups are rare. Block chain technology with its distributed data acquisition and storage capacity, unchangeable timestamp, etc. designed contract[6], after module 1 having completed the data collection and data transmission, combined with the front-end embedded decentralized risk pricing model and the terminal centralized risk pricing model. 
Borrower credit risk pricing is completed by the two centralized and decentralized systems together, constructing "centralized + decentralized" credit system based on the "block chain +".

\subsection{Terminal “centralized" management module (module 3)}

Block chain + credit system for the weak credit group, is the core of the whole credit system, including the centralized risk pricing model, credit information data system, and risk warning system [5] [7].

As mentioned above, the centralized risk pricing model is involved in the pricing decision process, providing information intermediary services for the borrowers and investors.

The credit information system, after having collected, sorted and handled the return data from module 1 and calculation results from module 2, uses machine learning techniques for data mining, providing upgrade maintenance for the risk pricing model of each module.

Risk warning system, through the time series analysis of credit data, gives the risk levels for spot and forecast, and feedbacks to the module 1 users, providing a reference for the correction of risk preferences.

\section{Conclusion}

During the development of consumer credit, the main problem is that the overall framework of the system design is not accurate positioning, access to credit information is not standardized, risk pricing model is not mature, and the technical route problem is not complete, which is closely and inseparably related to the existing status of the numerous consumer loan company, many of them even just idle social capital accumulation. This is not conducive to the effective development of consumer loans to reduce the cost of supervision. Through the above studies, the construction of credit system based on block chain as the underlying technology, effectively solves the problem of risk pricing for weak credit groups, enabling it to enter into financial transactions, access to liquidity support in the premise of maintaining the controllable risk.

\section{References}

[1] Block chain technology development present situation and prospect [J]. J Yuan Yong, fei-yue wang. Journal of automation. 2016(04)

[2] The analysis of the present situation of personal consumer credit and its countermeasures study [J]. J Wei Yijun. Consumer economy. 2005(05)

[3] The meaningful use of big data [J]. Christian Bizer, Peter Boncz, Michael L. Brodie, Orri Erling. ACM SIGMOD Record. 2012 (4)

[4] Consumer credit risk prevention legal issues research; Third, jinan university Consumer credit risk management of the rational model of default study [J].

[5] Journal of Ren Jinzheng, bao-feng Chen, Kuang HuanDi. Technical and economic. 2005(08)

[6] Decentralizing privacy: using blockchain to protect personal data. Zyskind G, Nathan O, Pentland A S. Proceedings of the 2015 IEEE Security and Privacy Workshops (SPW2015). 2015

[7] Credit reporting and Internet financial risk control [J] Jiang Qingjun, China's financial. 2016(06) 